\title{
Secrets of aging: What does a normally aging brain look like?
}

\section{Carol A. Barnes}

Address: Evelyn F. McKnight Brain Institute and Departments of Psychology and Neurology, University of Arizona, Life Sciences North, Rm 355 , Tucson, AZ 85724-5115, USA

Email: carol@nsma.arizona.edu

FI000 Biology Reports 20II, 3:22 (doi:I0.34I0/B3-22)

This is an open-access article distributed under the terms of the Creative Commons Attribution-Non Commercial License (http://creativecommons.org/licenses/by-nc/3.0/legalcode), which permits unrestricted use, distribution, and reproduction in any medium, provided the original work is properly cited. You may not use this work for commercial purposes.

The electronic version of this article is the complete one and can be found at: http://f1000.com/reports/b/3/22

\begin{abstract}
Over the past half century, remarkable progress has been made in understanding the biological basis of memory and how it changes over the lifespan. An important conceptual advance during this period was the realization that normative cognitive trajectories can exist independently of dementing illness. In fact, mammals as different as rats and monkeys, who do not spontaneously develop Alzheimer's disease, show memory impairments at advanced ages in similar domains as those observed in older humans. Thus, animal models have been particularly helpful in revealing brain mechanisms responsible for the cognitive changes that occur in aging. During these past decades, a number of empirical and technical advances enabled the discoveries that began to link age-related changes in brain function to behavior. The pace of innovation continues to accelerate today, resulting in an expanded window through which the secrets of the aging brain are being deciphered.
\end{abstract}

\section{Defining normative aging}

Only 40 years ago it was widely believed that if you lived long enough, you would eventually experience serious cognitive decline, particularly with respect to memory. The implication for cognition was that achieving an advanced age was effectively equivalent to becoming senile-a word that implies mental defects or a dementing illness. As a graduate student during that era, I was curious why such conclusions were being drawn about the elderly-especially since there appeared to be striking exceptions to this description of cognitive aging. A greatgrandmother and great-aunt on my father's side, for example, were fun to be with, exceptionally active and quick witted. A closer look at the extant literature did not give me confidence that either the biological basis of memory or how it might be expected to change with age was well understood. An explosion of discoveries were made over the intervening years-including major breakthroughs in understanding how memory is stored and retrieved by the brain. This along with other factors resulted in a major conceptual shift away from the view of "aging as a disease" and towards the view of "aging as a risk factor" for a number of neurological diseases. This encourages examination of the question of why some show successful aging trajectories that include perhaps annoying, but relatively minor, cognitive change, while others show significant and disabling memory decline. Answers to this type of inquiry are fundamental for understanding both how to prevent disease as well as how to promote quality of life. While there is a rich human literature on brain aging and cognition (e.g., [1]), many insights about the details of brain aging have come from the study of animal models, and the latter is the focus of the current review.

\section{Spatial memory and long-term potentiation in aging}

The gradual inability to recall the past or to retain new information describes the erosion that occurs in those who do become "demented" at older ages. In the end, the rich set of recollections available from past events defines each individual. Although many other changes occur during the aging process, such as limitations in range of motion, speed of gait, and acuity of vision and hearing, none of these factors are as central to the core of a person as are their collective experiences. Thus, the 
quest to understand memory and how it is changed during aging and in disease is a compelling problem.

As a graduate student in the 1970s, I remember listening to neuroscience lectures about how scientists such as Santiago Rámon y Cajal-often cited as the father of modern neuroscience-were able to use relatively simple microscopes to make fundamental discoveries. Rámon y Cajal used Camillo Golgi's silver chromate cell-staining method to view single neurons in the brain, and speculated that these neurons might communicate with one another through specialized contact points. Charles Sherrington would later call this critical point between cells "the synapse". In 1949 Donald Hebb articulated the idea that the laying down of "memory traces" in the brain would require a strengthening in the ability of one cell to influence another. This increase in the strength of synapses would then allow more reliable communication between one cell and another [2]. But how could you test these ideas about memory traces in the brain and whether there was a breakdown in synaptic communication during aging?

In 1973, Terje Lømo, Tim Bliss, and Tony GardnerMedwin devised a method that could experimentally change synaptic strength-a process the brain may use to lay down memory traces-that unlocked the door to the mystery of memory $[3,4]$. Here, for the first time, was a fully controllable, experimental proxy for learning. As it turns out, the discovery of this method, known as long-term potentiation (LTP), was a cornerstone in the evolution of our understanding of the biology of memory. Lømo et al. were electrophysiologists-they applied small electrical currents to a group of cells, and then measured the "collective" synaptic outputs. By giving stimulation patterns to the brain that mimicked normal electrical activity in neurons, a durable change in synaptic strength could be directly measured. For me in particular, LTP was the long-awaited tool that would allow the biological process of learning and memory to be studied. Importantly, it fulfilled a number of requirements proposed by Hebb for a process capable of laying down and retrieving memories. This discovery made it possible to study memory across the lifespan of an animal, using animal models of aging.

The critical missing link in making progress towards understanding what was "normal" in aging memory was "what behavior to study." Fortuitously, during the same time that LTP was discovered, a draft copy of a review article, which eventually morphed into the classic and influential book, The Hippocampus as a Cognitive Map [5] by John O'Keefe and Lynn Nadel, was being passed around among the professors of the department in which
I was a graduate student. It eventually found its way to my desk, and in it was a description of how the hippocampus likely had very similar functions in memory in humans and other animals. In particular, they outlined how spatial memory could be used across species to better understand memory in all animals, as it did not require language to be tested. John and Lynn's ideas encouraged my pursuit of questions that used animal models of the human condition, and that combined behavioral studies with neurobiological experiments that could interrogate how the brain acquires, stores, and retrieves information.

Thus, with the discovery of LTP at hippocampal synapses, and the idea that animal models of human memory could be developed, I sought to finish my dissertation experiments in a lab that was routinely conducting LTP experiments. In 1973, when I began to look, there were only three labs in the world that were doing these types of experiments: Graham Goddard's laboratory at Dalhousie University, Tim Bliss's in London, and Gary Lynch's at Irvine. As it turned out, my thesis advisor Peter Fried, at Carleton University in Ottawa, had been one of Goddard's students, and he introduced me to Goddard by saying, "I don't really want you to steal my student, but she has this idea that she thinks you might be interested in." I explained to Goddard that the experiment that I wanted to conduct in his lab involved methods that only his laboratory was currently using, namely surgically implanting indwelling electrodes so that LTP could be measured in awake, freely behaving rats. Since the hippocampus-the area of the brain where LTP was first discovered-was also involved in spatial memory, I wanted to use Goddard's setup to track an animal's ability to make and keep spatial memories as it aged. Remarkably, after Fried's phone call and introduction, and in an act of faith and generosity, Goddard purchased animals for me and began to "age" them in anticipation of my arrival the following year, after I had finished the rest of my course work and qualifying exams in Ottawa.

The behavioral tests used to study spatial memory at this time all required either shock (a significant stress) or a restricted eating or drinking schedule (also potentially detrimental to the survival of the old rats) to motivate animals. Because the precious aged animals could not be replaced without waiting two years to grow another "old" batch, we developed a novel, milder task that is now often referred to as the Barnes maze. With rodents' natural aversion to open, well-lit areas in mind, the circular platform was designed with many openings around its circumference, only one of which would allow the animal to escape into a dark box beneath the platform's surface. 
The rats were old enough to begin the behavior and electrophysiological experiments in the latter part of 1975 (at an age equivalent to about 70-80 human years). They were tested on the circular platform first before being permanently implanted with electrodes that could both stimulate hippocampal neurons and record their activity (a technique similar to deep brain stimulation for depression, epilepsy, and Parkinson's in humans), as well as allow the animals to walk unrestrained in a small holding cage while connected to the amplifiers and computers necessary to obtain their neurological responses. The electrodes implanted into the hippocampus of the young and old rats in Goddard's laboratory allowed us to measure baseline synaptic transmission with single stimuli, then to induce LTP with patterned electrical currents that mimic the way in which cells are normally active, and finally to monitor the LTP (or elevated synaptic strength) and watch its decay over several weeks. We found that LTP decayed about twice as fast in the old rats as it did in the young, with the "synaptic memory" lasting 20 days rather than 40. Most importantly, the durability of the synaptic change (LTP) was correlated with the memory of the correct hole on the circular platform task. In fact, the correlation between LTP durability in the hippocampus and spatial memory was the first demonstration that rather than a mere proxy for learning, LTP might actually represent at least one cellular mechanism by which memories are created [6].

Just one year before I published my work on aging rats, Bruce McNaughton [7] demonstrated that for synaptic strengthening to occur, many synpases needed to converge and be coactive on the target neuron. No modification would result if only one or a few synapses were active together (Graham Collingridge later found that this cooperativity effect resulted from the properties of a specific type of glutamate receptor-the newly discovered, voltage-dependent $\mathrm{N}$-Methyl-D-aspartic acid [NMDA] receptor [8]). This fulfills Hebb's requirement for cooperativity among synapses carrying multiple bits of information, reflecting the associations that must be made to store an experience. These experimental results had important theoretical implications that provided a foundation on which to build the interpretation of our aging findings from the experiments conducted in Goddard's laboratory [6]. In later experiments, others also demonstrated that under some conditions, LTP can be more difficult to induce in aged rats $[9,10]$, and a fascinating twist in the plasticity story is that mechanisms that reduce synaptic strength and weaken connections, known as long-term depression (LTD), are easier to induce in the hippocampus of old rats [11]. This may mean that LTD participates in 'erasing' LTP, potentially increasing forgetting. Taken together, it is clear that even in normal aging there are subtle changes in the biological processes that underlie memory, and in the relationship between how good an animal's memory is and how functional their synapses are. But the real message in these experiments is that old animals can and do learn. None of the older animals exhibited what could be considered behaviorally to be "dementia", nor were their biological mechanisms that allow memory traces to be laid down completely dysfunctional.

\section{Aging networks}

We know that plasticity mechanisms, LTP being one example, are altered at older ages, but what was not known was how this change in groups of cells that are artificially stimulated translates into the function of cells in behaviorally activated networks. While there is much to be learned about the physiology of neural systems by artificially stimulating them directly, even the mildest currents do not exactly mimic the selective and sparse activity of cells under normal behavioral states. To more realistically understand the aging brain, it was necessary to monitor cell circuits driven by natural behaviors. Around the time that LTP was discovered, John O'Keefe discovered "place cells" in the hippocampus-a major breakthrough for the field. By simply placing small microwires very close to hippocampal cells, without stimulating them, John and his student Jonathan Dostrovski noted that individual hippocampal cells discharge action potentials only when a rat is in select physical locations as it traverses a given environment [12]. In fact, this observation provided a major rationale for ideas outlined in the book, The Hippocampus as a Cognitive Map [5], which detailed evidence for a link between the hippocampus, memory, and space. The unique property of these place cells is that their "receptive fields", or the features that make each of these cells fire, appeared to be related to specific regions of space.

I went to O'Keefe's lab in London in 1981 to learn how to track the activity of these place cells in behaving young and old rats, the motivation being to gain a broader understanding of how changes in plasticity during aging may impact the operation of these cellular networks. In London that same year, Bruce McNaughton had the idea for a much more powerful recording method (the tetrode [13]), which could monitor and distinguish many cells at once in behaving rats. He developed the method further with Matt Wilson and they demonstrated that if enough hippocampal cells were recorded simultaneously, it was possible to reconstruct where the rat was in space, just by using the activity of the recorded cells [14]. For example, if cell A, B, and C had different, overlapping place fields 
along a route, and the rat passed through that route in a specific direction, cell $\mathrm{A}, \mathrm{B}$, and finally $\mathrm{C}$ would fire sequentially, illustrating how the locations of the elevated activity in specific hippocampal cells could predict where the animal had been. This new method provided an outstanding opportunity to examine the effects of age on hippocampal network dynamics.

By recording from many individual cells at once, and determining where each cell was active (where its place field was), it is possible to visualize how the hippocampus constructs a "cognitive map" of the surroundings. The collective firing of cells in different places can be thought of as a map or a representation of the context onto which episodes of experience are linked. Using this method, we were able to show that the hippocampal map within a session of behavior (running around a track for chocolate milk reward) was stable and reliable for both young and old rats. That is, once the rat was placed on the track, and began to run around it, each cell was only active in its preferred spot. Additionally, if young rats were given one track-running session in the morning, and another one in the afternoon, the same hippocampal map was retrieved in the afternoon as was present in the morning, suggesting between-session map stability. Here is where we made a critical observation about aging hippocampal networks. For the old rats, a different placecell distribution would occasionally appear when the rats went back for their second run of the day-it was as if the older animals were retrieving the wrong hippocampal map [15]. This did not happen every day, but any given old rat had about a 30\% chance that this would occur on any given day. Certainly if you are navigating your memory space with the wrong map, you are going to appear "lost", or as though you have forgotten your way. What could be the underlying cause of this unstable map?

The possible answer to this question was provided by Cliff Kentros, shortly after the aging observation was made. Cliff pharmacologically blocked the NMDA receptor in young animals, using a dose that also blocked LTP. His findings were strikingly reminiscent of the aging rats just described-within a given recording session, the map was stable-but blocking LTP caused map retrieval errors when a second session was given on the same day [16]. This suggested that faulty LTP mechanisms may be responsible for this map instability in aging.

\section{Normative aging can be distinguished from pathological aging in large scale neural circuits}

Even though the new multiple tetrode recording method was a large advance over the limitations of recording one or two neurons at a time, as previous technologies allowed, these methods are still constrained to samples sizes of $\sim 100-200$ cells. With recent improvements in the resolution of magnetic resonance imaging (MRI) methods, and the discovery of genes whose expression can dynamically monitor the activity of single neurons, human, primate, and rat studies have begun to converge on the identification of circuits most affected by the normal aging process. Some of the new, genetic links to memory have been particularly revealing. One of these is the immediate early gene that Paul Worley has called Arc (encoding the activity-regulated cytoskeleton-associated protein) ([17], cf. [18]). This gene has at least two features that are important with respect to understanding normative aging processes. First, normal function of Arc is necessary for durable LTP and lasting memories (both of which are impaired in aging; e.g., [19]). I want to emphasize another dimension, however, which is the fact that Arc expression within individual cells is a powerful and reliable indicator of cell activity-both inside the hippocampus, and across many regions of the brain. Using the property of Arc that allows readout of behavior-driven cell activity, John Guzowski developed a method that could monitor activity over hundreds of thousands of cells across the brain (the 'catFISH' method) [20]. Using this single-cell imaging method, an understanding is emerging of which cells, within which memory circuits, are particularly affected by aging. It is important to understand that the hippocampus is not a unitary structure-there are three primary cell groups within the hippocampus proper that combine to make up the internal circuit. These include the CA1 and CA3 pyramidal cells, and the granule cells of the dentate gyrus. Cells in the entorhinal cortex provide the hippocampus with its primary input, and cells in the subiculum serve as the primary output from the hippocampus. We were able to show that in aging rats, cell-specific gene expression (and therefore cell activity) was identical across age in the cells of the CA1 and CA3 regions, but the Arc catFISH method revealed that the number of granule cells engaged by these same behaviors showed a continuous decline across age. In terms of overall circuit function, these data point to the dentate gyrus as being a weak link in the hippocampal circuit during aging in the rat. Could this also be true in primates?

Scott Small joined in with my laboratory on an experiment to answer this question in young and old behaviorally characterized monkeys. Although MRI methods do not have single-cell resolution, they can provide an indirect gauge of activity over large segments of the brain. Using a variation of standard MRI methods (cerebral blood volume), it is possible to monitor the 
function of the brain in a resting state, and to look at activity in different components of the hippocampus as well as in its input and output structures. We applied these cerebral blood volume imaging methods to a colony of monkeys ranging in age from 9 to 27 years old (equivalent to 27-87 human years). There were no differences in resting metabolic measures in CA1, subiculum, or entorhinal cortex over this age range. But the old monkeys did show reduced activity selective to the dentate gyrus-reminiscent of the Arc imaging findings in our aging rats [21]. Critically, there was a significant correlation between the brain activity measure in the region of the dentate gyrus and memory in the aging monkeys-the lower the activity, the poorer the memory. Scott had observed something similar in an earlier human aging study [22]. With human studies, however, there is always some concern that some of the people tested, while seemingly normal at the time, may be showing the beginnings of neurological symptoms. Because only humans contract Alzheimer's disease, not other animals, the monkey and rat experiments were critical for the overall interpretation of the human data. By examining aging in animals who do not spontaneously get this disease, a very strong case can be built that the dentate gyrus is a major player in the changes that occur in normal aging in mammals.

The findings just reviewed led to an important insight, when combined with what is known about which temporal lobe regions are affected in diseases such as Alzheimer's. In the case of Alzheimer's disease, the cells in CA1 and in the entorhinal cortex are dramatically affected early in the course of the disease; however, in the same individuals, the granule cells of the dentate gyrus do not show changes (with respect to age-matched controls) until very late in the illness. While aging and Alzheimer's disease may in some cases be "superimposed", there is not a simple linear trajectory where we all end up with the disease. Rather, aging has a different neural signature, supporting the contention that aging and Alzheimer's disease are distinct $[23,24]$.

\section{Understanding genetic and epigenetic processes that guide successful aging trajectories}

Presently, the "omic" revolution may be leading us as close as we have ever been to understanding why one of a pair of identical human twins can maintain a high level of cognition during aging, while the other does not. Technological advances in understanding the details of individual genomes are progressing at an almost breathtaking speed. One example with respect to memory is a study that used a single nucleotide polymorphism (SNP) genome-wide association approach in young adults to identify SNPs that were most strongly related to memory performance. The SNP identified was a simple nucleotide base switch between the normal cytosine-thymine bond at a specific location in the KIBRA gene. The people surveyed who had the thymine-thymine SNP had the best memory [25]. This was further confirmed in an independent elderly population, supporting the view that this particular SNP in the KIBRA gene predisposed people of any age to have "better memory" [26]. This could be another clue to help guide our understanding of the molecular cascades that support good memory; plus, the activity of the KIBRA gene does influence pathways involved in synaptic strengthening previously mentioned. Could there be a link between the KIBRA gene and age-related memory decline? One way to test this hypothesis was to find a way to manipulate part of the molecular circuit in which the KIBRA gene is known to be involved. These are the kinds of experiments that rarely work, but Matt Huentelman persevered and found a promising compound that was already approved for use in treatment of angina. Quite remarkably, and as predicted, hydroxyfasudil improved spatial learning and working memory in aged rats [27].

In addition to methods that can accurately identify variations in DNA in individuals, we now know that epigenetic factors are engaged not only during early development (as these mechanisms were classically described), but also in adulthood. Another paradigmshifting observation in very recent years has been that chromatin can be remodeled in the hippocampus in response to learning [28]. The thought that your DNA is continually being modified is somewhat disconcerting. While the experimental progress in this area is picking up speed, it took a long time for the scientific community to be comfortable with this idea. But the data are the data; in fact, it appears that some of the age-related changes in memory are likely to be due to alterations in the epigenetic modification of chromatin-via both acetylation [29] and methylation [30] mechanisms. For example, as Marsha Penner was finishing her $\mathrm{PhD}$ thesis in my lab on behavior-induced Arc expression in young and old rats she had an interesting insight: maybe the changes observed in Arc mRNA expression, such as fewer hippocampal granule cells expressing Arc in response to behavior, were partly due to altered RNA transcription processes in aging. One way transcription can be reduced, of course, is through altered DNA methylation processes.

David Sweatt recently showed changes in DNA methylation state in response to learning, and he was very interested in collaborating with us to determine whether changes in this process during aging might explain our Arc data. More methylation of DNA typically means that there is less RNA transcribed. Following behavior, the 
methylation state of the Arc gene was, in fact, reduced in both age groups (a condition that allows more of the Arc mRNA to be transcribed). The factor that differed between young and old animals was that in the resting old brain, granule cells, for example, had overall higher methylation levels, meaning that it was less likely that Arc could be transcribed from the DNA. There are many complex facets of these data, but these kinds of results have led us and others to hypothesize that there may well be a number of changes that accumulate during aging via epigenetic means, and that dysregulation of these processes may contribute in a fundamental way to normal age-related cognitive change. While the details of exactly how aging affects histone posttranslational modifications and alterations in DNA methylation remain to be elucidated, it is at least safe to guess that these mechanisms will be critical to understand for future experimental designs aimed at optimizing cognition across the lifespan. These processes are also amenable to pharmacological manipulation.

\section{Conclusions}

Looking back on the rather grim predictions concerning memory and the elderly that were held only several decades ago, the vision today is very different and much more positive. There are many who live to very old ages with minimal cognitive decline-and certainly no dementia. One particularly interesting study in this regard was done in Sweden with individuals who were 100 years of age (centenarians) at the beginning of the study, who were followed longitudinally until the time of their death to monitor cognitive function and other factors in the "oldest old" [31]. Interestingly, 73\% of these centenarians were dementia free at the end of their lives (the oldest reaching an age of 111 years). Watching the remarkable discoveries in biology over the past half century, one cannot help but look with excitement towards the next groundbreaking findings that are surely in the making. The future holds great promise for the once remote dream of being able to understand the core biological processes required for optimal cognitive health during aging-our progress in this regard should also provide the needed backdrop for understanding and preventing the complex neurological diseases that can be superimposed on the aging brain.

\section{Abbreviations}

LTD, long-term depression; LTP, long-term potentiation; MRI, magnetic resonance imaging; NMDA, N-Methyl-Daspartic acid; SNP, single nucleotide polymorphism.

\section{Competing interests}

The author declares she has no competing interests.

\section{References}

I. Park DC, Reuter-Lorenz P: The adaptive brain: Aging and neurocognitive scaffolding. Annu Rev Psychol 2009, 60:173-196.

2. Hebb DO: The Organization of Behavior. New York: John Wiley \& Sons; 1949.

3. Bliss TVP, Gardner-Medwin AR: Long-lasting potentiation of synaptic transmission in the dentate area of the unanaesthetised rabbit following stimulation of the perforant path. J Physiol 1973, 232:357-74.

FI000 Factor 8

Evaluated Carol Barnes 19 Sep 2011

4. Bliss TVP, Lomo $\mathrm{T}$ : Long-lasting potentiation of synaptic transmission in the dentate area of the anesthetized rabbit following stimulus of perforant path. J Physiol 1973, 232:331-56.

FI000 Factor 8

Evaluated Carol Barnes 19 Sep 2011

5. O'Keefe J, Nadel L: The hippocampus as a cognitive map. Oxford: Clarendon Press; 1978.

6. Barnes CA: Memory deficits associated with senescence: A neurophysiological and behavioral study in the rat. J Comp Physiol Psychol 1979, 93:74-104.

7. McNaughton BL, Douglas RM, Goddard GV: Synaptic enhancement in fascia dentata: Cooperativity among coactive afferents. Brain Res 1978, I57:277-93.

FI000 Factor 8

Evaluated Carol Barnes 19 Sep 201 I

8. Collingridge G, Kehl S: Excitatory amino acids in synaptic transmission in the Schaffer collateral-commissural pathway of the rat hippocampus. J Physiol 1983, 334:3-46.

FI000 Factor 6

Evaluated Carol Barnes 19 Sep 2011

9. Deupree DL, Bradley J, Turner DA: Age-related alterations in potentiation in the CAI region in F344 rats. Neurobiol Aging 1993, 14:249-58.

FI000 Factor 6

Evaluated Carol Barnes 19 Sep 201I

10. Moore $\mathrm{Cl}$, Browning MD, Rose GM: Hippocampal plasticity induced by primed burst, but not long-term potentiation, stimulation is impaired in area CAI of aged Fischer 344 rats. Hippocampus 1993, 3:57-66.

FI000 Factor 6

Evaluated Carol Barnes 19 Sep 2011

II. Norris CM, Korol DL, Foster TC: Increased susceptibility to induction of long-term depression and long-term potentiation reversal during aging. J Neurosci 1996, 16:5382-92.

FI000 Factor 8

Evaluated Carol Barnes 19 Sep 201I

12. O'Keefe J, Dostrovsky J: The hippocampus as a spatial map. Preliminary evidence from unit activity in the freely-moving rat. Brain Res 1971, 34:171-5.

FI000 Factor 10

Evaluated Carol Barnes 19 Sep 20II

13. McNaughton BL, O'Keefe J, Barnes CA: The stereotrode: A new technique for simultaneous isolation of several single units in the central nervous system from multiple unit records. J Neurosci Methods 1983, 8:391-7.

14. Wilson MA, McNaughton BL: Dynamics of the hippocampal ensemble code for space. Science 1993, 26 I:1055-8.

FI000 Factor 6

Evaluated Carol Barnes 19 Sep 2011 
15. Barnes CA, Suster MS, Shen J, McNaughton BL: Multistability of cognitive maps in the hippocampus of old rats. Nature 1997 , 388:272-5.

16. Kentros C, Hargreaves E, Hawkins RD, Kandel ER, Shapiro M, Muller RV: Abolition of long-term stability of new hippocampal place cell maps by NMDA receptor blockade. Science 1998, 280:2I $21-6$

\section{FI000 Factor 6}

Evaluated Carol Barnes 19 Sep 2011

17. Lyford GL, Yamagata K, Kaufmann WE, Barnes CA, Sanders LK, Copeland NG, Gilbert DJ, Jenkins NA, Lanahan AA, Worley PF: Arc, a growth factor and activity-regulated gene, encodes a novel cytoskeleton-associated protein that is enriched in neuronal dendrites. Neuron 1995, 14:433-45.

18. Link W, Konietzko U, Kauselmann G, Krug M, Schwanke B, Frey U, Kuhl D: Somatodendritic expression of an immediate early gene is regulated by synaptic activity. Proc Natl Acad Sci U S A, 1995, 92:5734-8.

19. Guzowski JF, Lyford GL, Stevenson GD, Houston FP, McGaugh JL, Worley PF, Barnes CA: Inhibition of activity-dependent Arc protein expression in the rat hippocampus impairs the maintenance of long-term potentiation and the consolidation of long-term memory. J Neurosci 2000, 20:3993-400I.

20. Guzowski JF, McNaughton BL, Barnes CA, Worley PF: Environmentspecific expression of the immediate-early gene Arc in hippocampal neuronal ensembles. Nat Neurosci 1999, 2: I I 20-4.

21. Small SA, Chawla MK, Buonocore M, Rapp PR, Barnes CA: Imaging correlates of brain function in monkeys and rats isolates a hippocampal subregion differentially vulnerable to aging. Proc Natl Acad Sci U S A 2004, 101:7181-6.

22. Small SA, Tsai WY, DeLaPaz R, Mayeux R, Stern Y: Imaging hippocampal function across the human life span: Is memory decline normal or not? Ann Neurol 2002, 51:290-5.

FI000 Factor 6

Evaluated Carol Barnes 19 Sep 201I

23. Nelson PT, Head E, Schmitt FA, Davis PR, Neltner JH, Jicha GA, Abner EL, Smith CD, Van Eldik LJ, Kryscio RJ, Scheff SW: Alzheimer's disease is not "brain aging": Neuropathological, genetic, and epidemiological human studies. Acta Neuropathol 20II, I 2 I:57I-87.

FI000 Factor 6

Evaluated Carol Barnes 19 Sep 2011

24. Wu W, Brickman AM, Luchsinger J, Farrazano P, Pichiule P, Brown T, DeCarli C, Barnes C, Mayeux R, Vannucci S, Small SA: The brain in the age of old: The hippocampal formation is targeted differentially by diseases of late-life. Ann Neurol 2008, 64:698-706.

25. Papassotiropoulos A, Stephan DA, Huentelman MJ, Hoerndli FJ, Craig DW, Pearson JV, Huynh KD, Brunner F, Corneveaux J, Osborne D, Wollmer MA, Aerni A, Coluccia D, Hänggi J, Mondadori CR, Buchmann A, Reiman EM, Caselli RJ, Henke K, de Quervain DJ: Common Kibra alleles are associated with human memory performance. Science 2006, 3 I 4:475-8.

FI000 Factor 13

Evaluated by David P Wolfer 30 Oct 2006, Hansvan Bokhoven 31 Oct 2006, Alejandro Schaffer 06 Nov 2006, Carol Barnes 19 Sep 2011

26. Schaper K, Kolsch H, Popp J, Wagner M, Jessen F: KIBRA gene variants are associated with episodic memory in healthy elderly. Neurobiol Aging 2008, 29: I | 23-5.

FI000 Factor 6

Evaluated Carol Barnes 19 Sep 2011

27. Huentelman MJ, Stephan DA, Talboom J, Corneveaux JJ, Reiman DM, Gerber JD, Barnes CA, Alexander GE, Reiman EM, BimonteNelson HA: Peripheral delivery of a ROCK inhibitor improves learning and working memory. Behav Neurosci 2009, 123:2।8-23.

28. Swank MW, Sweatt JD: Increased histone acetyltransferase and lysine acetyltransferase activity and biphasic activation of the ERK/RSK cascade in insular cortex during novel taste learning. J Neurosci 200I, 21:3383-9I.

FI000 Factor 8

Evaluated Carol Barnes 19 Sep 2011

29. Peleg S, Sananbenesi F, Zovoilis A, Burkhardt S, Bahari-Javan S, Agis-Balboa RC, Cota P, Wittnam JL, Gogol-Doering A, Opitz L, Salinas-Riester G, Dettenhofer M, Kang H, Farinelli L, Chen W, Fischer A: Altered histone acetylation is associated with age-dependent memory impairment in mice. Science 2010 , 328:753-6.

FI000 Factor 13

Evaluated Carol Barnes 19 Sep 2011

30. Penner MR, Roth TL, Chawla MK, Hoang LT, Roth ED, Lubin FD, Sweatt DJ, Worley PF, Barnes CA: Age-related changes in Arc transcription and DNA methylation within the hippocampus. Neurobiol Aging 20I I, [Epub ahead of print].

3I. Haberg G, Samuelsson G: Survival after 100 years of age: a multivariate model of exceptional survival in Swedish centenarians. J Gerontol A Biol Sci Med Sci 2008, 63:1219-26.

FI000 Factor 8

Evaluated Carol Barnes 19 Sep 2011 